\title{
Vertebral Artery Dissect Injury with Brown-Séquard Syndrome by a Neural Foramen Penetrated Electric Screw Driver Bit: A Case Report
}

\author{
Chang Hyun $\mathrm{Oh}^{1}$, Min Soo Kim², Sung Hyun $\mathrm{Noh}^{2}$, Dong Ah Shin ${ }^{3}$, Gyu Yeul $\mathrm{Ji}^{3}$ \\ ${ }^{I}$ Department of Neurosurgery, Guro Teun Teun Hospital, Seoul, \\ ${ }^{2}$ Department of Neurosurgery, CHA Bundang Medical Center, CHA University, Seongnam, \\ ${ }^{3}$ Department of Neurosurgery, Spine and Spinal Cord Research Institute, Yonsei University College of Medicine, Seoul, Korea
}

There are few reports in the literature of complete obstruction of the vertebral artery (VA) due to an electric screw driver bit penetration through the neural foramen into the spinal canal with Brown-Séquard syndrome (BSS). A 25-year-old man was admitted to the emergency department with a penetrated neck injury by an electric screw driver bit after a struggle. The patient presented the clinical features of BSS. Computed tomography scan revealed that the electric screw driver bit penetrated through the right neural foramen at the level of C3-4, and it caused an injury to the right half of the spinal cord. Emergent angiography revealed VA dissection, which was managed by immediate coil embolization at both proximal and distal ends of the injury site. After occlusion of the VA, the electric screw driver bit was extracted under general anesthesia. Bleeding was minimal and controlled without difficulties. No postoperative complications, such as wound dehiscence, CSF leakage, or infection, were noted. Endovascular approaches for occlusion of vertebral artery lesions are safe and effective methods of treatment.

Key Words: Cervical vertebrae $\cdot$ Penetrating wound $\cdot$ Brown- Séquard syndrome $\cdot$ Vertebral artery dissection $\cdot$ Embolization

\section{INTRODUCTION}

Brown-Séquard syndrome (BSS), which occurs due to dysfunction of the spinothalamic tract, typically reflects the hemisection of the spinal cord at the cervical or thoracic level. The syndrome mainly occurs as a result of penetrating trauma, syringomyelia, hematomyelia, tumor, severe discs, or blunt trauma. Among the multiple etiologies, the most common cause is penetrating trauma, such as a gunshot ${ }^{7,8)}$. Therefore,

- Received: September 4, 2013 - Revised: November 29, 2013

- Accepted: December 2, 2013

Corresponding Author: Dong Ah Shin, MD, PhD

Department of Neurosurgery, Spine and Spinal Cord Research Institute, Yonsei University College of Medicine 50, Yonsei-ro, Seodaemun-gu, Seoul 120-752, Korea

Tel: +82-2-2228-2150, Fax: +82-2-393-9979

E-mail: shindongah@me.com

* This study was supported by a grant of the Korea Healthcare technology R\&D project, Ministry for Health \& Welfare Affairs, Republic of Korea (A111016)

* The authors declare that they have no proprietary, commercial, or financial interests that could be construed to have inappropriately influenced this study.

* This study has not been presented in part elsewhere.

$\otimes$ This is an Open Access article distributed under the terms of the Creative Commons Attribution Non-Commercial License (http://creativecommons.org/ licenses/by-nc/3.0/) which permits unrestricted non-commercial use, distribution, and reproduction in any medium, provided the original work is properly cited. most management guidelines focus on penetrating cervical injuries and/or vertebral artery (VA) injury ${ }^{12}$. Non-missile penetrating spinal cord and VA injuries are rare because of the bony structures that protect the spinal cord and $\mathrm{VA}^{14)}$. Thus, the treatment approach for wounds caused in non-missile penetrating spinal injuries such as a knife, a power drill bit, or even a pen could be different from common missile penetrating injuries ${ }^{5,6,13,17)}$.To our knowledge, there are few reports in the literature of complete obstruction of the VA due to penetration of a foreign body through the neural foramen into the spinal canal. Herein, the authors report on VA dissection and BSS caused by penetration of an electric screw driver bit.

\section{CASE REPORT}

A 25-year-old machine operator was involved in a violent episode and was stabbed in his right neck with an electric screw driver bit that was thrown by the opponent. On arrival at the emergency department, the electric screw driver bit was placed in the right lateral aspect of the neck at zone I (Fig. 1A). The patient was mentally alert and vital signs were stable. The tip of the electric screw driver bit was located at the center of the vertebral canal of C3 (Fig. 1B, C). Neurologic examination revealed ipsilateral spastic paralysis (Uex. GI/Lex. 

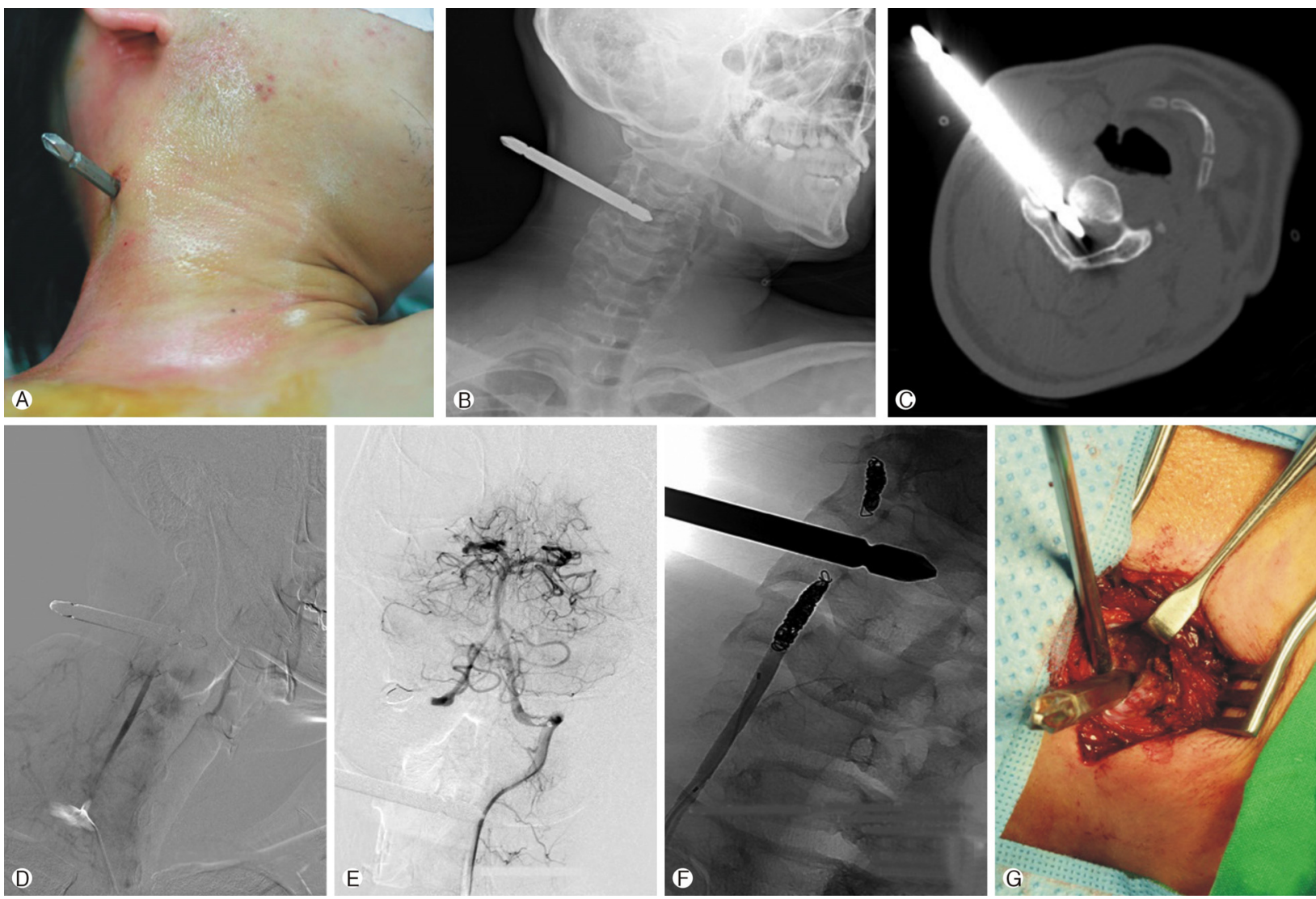

Fig. 1. Clinical images: Pre-operative photography (A), radiograph (B), and axial cervical computed tomography (C) demonstrated an offending instrument penetrating through the right transverse foramen to the vertebral canal of $\mathrm{C} 3$. The angiography revealed total occlusion of the right VA (D) and well good cross filling of the branches of the right VA from the left VA (E). After endovascular coil embolization (F), the foreign body was removed under the general anesthesia (G): VA; vertebral artery

GI) with contralateral loss of pain and temperature sensation. $\mathrm{He}$ was given high-dose methylprednisolone (bolus dose of $30 \mathrm{mg} / \mathrm{kg}$ followed by $5.4 \mathrm{mg} / \mathrm{kg} /$ hour for 23 hours) according to the protocol for spinal cord injury. An immediate interventional angiography was undertaken without general anesthesia due to the nature of the emergency. The angiography revealed a total occlusion with dissection of the right VA at the level of C3. Left VA angiography showed good cross filling of the branches of the right VA (Fig. 1D, E). Subsequently, immediate coil embolization at both proximal and distal ends of the injury site was performed (Fig. 1F). An attempt at manual extraction of the electric screw driver bit failed with great resistance. After the patient was moved to the operating room, the electric screw driver bit was removed manually with muscle dissection under general anesthesia. Venous blood spilled out and was controlled easily by application of several pieces of gelatin sponge. No postoperative complications such as wound dehiscence, cerebrospinal fluid (CSF) leakage, or infection were observed. The patient's neurologic function gradually improved, and he underwent rehabilitation. The neuro- logical motor function of the right upper and lower extremities recovered to $3 / 5$ and $4 / 5$, respectively, with persistent decreased sensory function after one year. Fortunately, the patient experienced no neck swelling, auscultation of a neck bruit, or delayed ischemic complications.

\section{DISCUSSION}

Penetrating injury is the third most frequent cause of spinal cord injury in adults, surpassed only by traffic accidents and falls $^{3,18)}$. Most penetrating neck injuries are caused by knives and low-energy gunshot wounds. Stab wounds are associated with lesser surrounding tissue injury than gunshot wounds because the former delivers less energy than missile injuries". Although vascular injury is the most common sequel of penetrating neck trauma, VA injury is rare because it is well protected by the transverse foramen ${ }^{4,10)}$. Therefore, penetrating injury of the VA is mostly caused by gunshot wounds which deliver large kinetic energy, depending upon the bullet's mass 
and speed ${ }^{12)}$. In this article, we report a rare case of VA penetration by an electric screw driver bit with spinal cord insult, consequently presenting as BSS. Moreover, surgical exploration of the VA can cause additional damage to the spine and surrounding tissues. Therefore, it may be reasonable to embolize an occluded artery, because the unilateral ligation of the VA rarely results in brainstem ischemia ${ }^{11,16}$. There are a few reports regarding the treatment of traumatic VA injury such as the arteriovenous fistulas and pseudoaneurysms ${ }^{2}$. Patients with penetrating cervical vascular injuries have high rates of mortality. Emergent surgical exploration is necessary for patients with hard signs of vascular injury, such as hemodynamic instability, hemorrhage exsanguinations, or expanding hematoma ${ }^{15)}$. Patients that are hemodynamically stable and who are without respiratory compromise should undergo further diagnostic imaging evaluation ${ }^{15}$. As presented in this case, endovascular techniques were a safe and effective method of treatment and were not associated with significant morbidity or mortality ${ }^{1}$. Close cooperation between surgeons and anesthesiologists is crucial during exploration. Airway management, intubation methods, and surgical positions can be points of debate between anesthesiologists and surgeons". If a lacerated VA can be successfully obliterated, a penetrating electric screw driver bit may be extracted without general anesthesia. Nevertheless, the authors recommend that surgeons should be prepared for conversion to open surgery and extraction should be performed with the support of a surgical team. We initially tried to extract the electric screw driver bit manually without general anesthesia in the intervention theater after VA embolization. However, the electric screw driver bit was positioned firmly in the neural foramen, and the patient complained of severe pain when the electric screw driver bit was being pulled out. In addition, there was more important rationale that justified surgical exploration for extraction of the electric screw driver bit. On extraction of the electric screw driver bit, there was unexpected venous bleeding that needed to be stopped. Moreover, there may have been CSF leakage that needed to be corrected. The authors describe a rare case of penetrating cervical injury caused by an electric screw driver bit with accompanying VA penetration and BSS. The case was successfully managed by preoperative angiographic embolization and subsequent surgical removal.

\section{Grant Information/other Acknowledgments}

This study was supported by a grant of the Korea Heal- thcare technology R\&D project, Ministry for Health \& Welfare Affairs, Republic of Korea (A111016).

\section{REFERENCES}

1. Gifford SM, Deel JT, Dent DL, Seenu Reddy V, Rasmussen TE: Endovascular repair of innominate artery injury secondary to air rifle pellet: a case report and review of the literature. Vasc Endovascular Surg 43:301-305, 2009

2. Herrera DA, Vargas SA, Dublin AB: Endovascular treatment of traumatic injuries of the vertebral artery. Am J Neuroradiol 29:1585-1589, 2008

3. Jallo GI: Neurosurgical management of penetrating spinal injury. Surg Neurol 47:328-330, 1997

4. Jean WC, Barrett MD, Rockswold G, Bergman TA: Gunshot wound to the head resulting in a vertebral artery pseudoaneurysm at the base of the skull. J Trauma 50:126-128, 2001

5. Lee HM, Kim NH, Park CI: Spinal cord injury caused by a stab wound--a case report. Yonsei Med J 31:280-284, 1990

6. Moin H, Khalili HA: Brown Sequard syndrome due to cervical pen assault. J Clin Forensic Med 13:144-145, 2006

7. Oller DW, Boone S: Blunt cervical spine Brown-Sequard injury. A report of three cases. Am Surg 57:361-365, 1991

8. Peacock WJ, Shrosbree RD, Key AG: A review of 450 stabwounds of the spinal cord. S Afr Med J 51:961-964, 1977

9. Prasad MK, Sinha AK, Bhadani UK, Chabra B, Rani K, Srivastava B: Management of difficult airway in penetrating cervical spine injury. Indian J Anaesth 54:59-61, 2010

10. Reid JD, Weigelt JA: Forty-three cases of vertebral artery trauma. J Trauma 28:1007-1012, 1988

11. Roberts LH, Demetriades D: Vertebral artery injuries. Surg Clin North Am 81:1345-1356, 2001

12. Rodriguez M, Tyberghien A, Matge G: Asymptomatic vertebral artery injury after acute cervical spine trauma. Acta Neurochir 143:939-945, 2001

13. Russell JH, Joseph SJ, Snell BJ, Jithoo R: Brown-Sequard syndrome associated with Horner's syndrome following a penetrating drill bit injury to the cervical spine. J Cin Neurosci 16:975- 977, 2009

14. Seong-Rok Han, Sang-Won Yoon, Gi-Taek Yee, Moon-Jun Sohn, Choong-Jin Whang: An Unusual Stab Injury of the Cervical Spinal Cord. Korean J Spine 2(2):184-187, 2005

15. Tan Z, Tian R, Yu ZY: Surgical management of penetrating cervical vascular trauma. Zhonghua Yi Xue Za Zhi 92:1905- 1908, 2012

16. Thomas GI, Anderson KN, Hain RF, Merendino KA: The significance of anomalous vertebral-basilar artery communications in operations on the heart and great vessels: an illustrative case with review of the literature. Surgery 46:747-757, 1959

17. Valero R, Serrano S, Adalia R, Tercero J, Blasi A, Sánchez-Etayo $\mathrm{G}$, et al: Anesthetic management of a patient in prone position with a drill bit penetrating the spinal canal at $\mathrm{C} 1-\mathrm{C} 2$, using a laryngeal mask. Anesth Analg 98:1447-1450, 2004

18. Yamaguchi S, Eguchi K, Takeda M, Hidaka T, Shrestha P, Kurisu K: Penetrating injury of the upper cervical spine by a chopstick--case report. Neurol Med Chir (Tokyo) 47:328-330, 2007 